\title{
Between Sociological Theory and Professional Practice: Integration Experiences in University Traineeship Programmes
}

\author{
Marco Accorinti \\ Institute for Research on Population and Social Policies of Rome (IRPPS), Rome, Italy
}

\begin{abstract}
This paper presents a reflection on the integration of sociology and social work into a degree programme offered by the Faculty of Sociology of Sapienza University of Rome. In particular, it explores the experience of designing the course (in accordance with the provisions contained in Ministerial Decree No. 509 of 3 November 1999 to Ministerial Decree No. 270 of 22 October 2004) and the training pathway for both social workers and sociologists (and other social policy experts). The underlying vision is a perspective of social work that emphasises many sources of knowledge and the formalization of in-field experience.
\end{abstract}

Keywords: education, university, social work

\section{Introduction}

In Italy, university studies are structured in accordance with the provisions contained in the Decree of the Ministry of Education, University and Research No. 270 of 22 October 2004, which provides for three cycles (or levels) of studies. The first two cycles cover the entire university pathway, with a three-year first-cycle (or Bachelor's) degree programme and a two-year second-cycle (or Master's) degree programme (Laurea Magistrale). The third cycle is related to higher education.

In response to the new regulatory requirements, Sapienza University restructured its educational offering concerning social work and changed the set up of the course that it had put in place under the previous university system provided for in Ministerial Decree No. 509 of 3 November 1999. In particular, Sapienza University has been offering two first-cycle and one second-cycle (specialisation) degree programmes, initially in the Faculty of Sociology and now in the Department of Social and Economic Sciences.

This text does not intend to present technicalities and bureaucratic procedures, nor the formal complexity of the structure of a degree programme in social work. The idea is to reason on the logic and processes underlying the regulations of the Master's degree, which have been amended three times over the course of a few years. An attempt is made to outline the development of the curriculum of the Master's degree in social work, with a special focus on the traineeship programme and its integration with sociological and social work theory.

In the practice of Sapienza University, the typical implications of social workers' professional activities became increasingly important in the curriculum of the Master's degree in social work. Traineeship was helpful for both understanding organisational aspects (social research) and providing actual training. The knowledge

Marco Accorinti, Italian National Research Council (CNR) researcher, Institute for Research on Population and Social Policies of Rome (IRPPS). 
and the organisational and innovational processes of social services, placed in their specific contexts in time and space, were investigated and then studied by students. With this prospect, teachers (as well as students) with different cultural backgrounds (i.e., social work and sociology) helped to theorise social practice, based on the understanding and the study of the organisations and systems involved in social work. In designing teaching and traineeship work, the theoretical and practical implications of representing the organisational knowledge of social work were taken into account. Experts in both social research and social work interacted regularly to define the curriculum, classroom activities, the traineeship programme, final tests, etc.. The analysis of 10 years of experience is intended to show how the educational activity of the traineeship programme was organised, which integrated knowledge from different areas.

\section{The Transition to a New System}

\section{Previous Academic System}

With the change of the curriculum under Ministerial Decree 270/2004, the new course of the Master's degree has been based on the previous academic system and experience since the academic year 2010/2011, even though additional legal requirements were introduced. Among others, the 120 university credits (CFUs) can no longer be obtained by taking exams that are supplementary to the social work curriculum, and a traineeship programme is mandatory for all students.

The conceptual framework of the programme was based on the knowledge of a set of elements that can be summarised in the following eight points:

(a) methodological principles and techniques for analysing social phenomena;

(b) the functioning of European welfare models (including the Italian one) in terms of composition, aims, action strategies, main stakeholders, and relevant agencies;

(c) rules and directives on social policies and services issued at a European, domestic, regional, and local level;

(d) the functioning of central and local governments and public services;

(e) theories and procedures for assessing policies and social services;

(f) forms of interaction among public, private, and third sector organisations;

(g) partnership mechanisms (outsourcing, accreditation, etc.) at a local level;

(h) consultation and participation of citizens, including in associative forms.

Most students were neither experienced social workers who wanted to keep themselves abreast of current developments, nor sociologists with an inclination towards social aid. They were either students from the relevant three-year degree programme (hence, with little experience of social work, but the traineeship hours) or students from other degree programmes, who could directly access the course under the new regulations, without any additional academic requirements (obblighi formativi). During the initial years, students who were not social workers were advised to take courses related to the profession of social worker (these courses had to be paid for and included in the students' overall study paln. In practice, there was a clear-cut differentiation between social worker students and non-social worker students, within a course that was originally designed as a specialisation in social work. Moreover, ministerial directions did not provide for the possibility to define "additional academic requirements" in the students' study plan. Hence, the programme had to be designed as a single course with 120 CFUs. 


\section{Renew Academic System}

However, in order to continue offering education to non-social-worker students, as the teaching staff considered this to be a positive experience, the Dean of the Faculty tried to pursue two avenues. The idea was to keep the vocation of the course, that is to say, vocational training in a large area of social work, with some possible differences in terms of goals and carrier opportunities. To this end, the Dean had tried to intervene in the very complex university framework and had initially designed the first year as common to all students, with two options for the second year: Curriculum A-Professional Coordination of Social Services (specifically for students who were already social workers); and Curriculum B-Analysis and Assessment of Social Policies and Services. The two curricula were intended for people with two different backgrounds entering (but also leaving) the programme. They differed in terms of educational approach more than in terms of the number or type of exams to be taken. For one of the curricula, the 120 CFUs of the programme included 10 CFUs under the heading "other educational activities," consisting of the "in-depth work in professional areas" of social work, in accordance with what was specified in the first project authorised by the university. The choice was to design an education activity that could be about practical experience and in-depth analysis, while waiting for national decisions to be taken in consultation with the professional association.

However, since it was not possible to have different curricula, the Dean of the faculty decided to introduce more social work courses, focusing on traineeship and using the skills of expert social workers and sociologists. Experts in assessment, research methodology, and policy analysis were directly involved in research on social services. Moreover, professionals with expertise in social services were engaged to teach in workshops about specific professional practice.

Students were required to attend at least $70 \%$ of workshop hours. Workshops included a final test, with each student writing and discussing an original paper, and it was to be used also for the final thesis at the end of the degree programme. To help students, especially those who had a job, workshops were timetabled as four-hour classes on Fridays and Saturdays. Each workshop consisted of seven classes, for a total of 32 hours of work (including classroom activity and individual work).

The programme offered six workshops in the first year and five in the second year. Students had to choose three of these workshops, plus one for their traineeship. All students had to take a compulsory module, Essential Assistance Levels (LIVEAS), whereas they could choose the other modules, which were offered in one of the two academic semesters. For the first experimental year, the traineeship consisted of 150 hours (certified), including some time (approximately 20 hours) for planning activities. The traineeship projects were developed by students themselves, agreed with the supervisor (a social worker) and approved by the traineeships coordinator. Furthermore, the traineeships did not provide for contacts with the users of services, as they were not about social assistance.

Besides LIVEAS workshops, the other workshops were the following: Support for Accessing Care Services (Social Secretariat); Complex Interventions with Children; Social and Occupational Integration; The Organisational Relation: Professional Culture and Practices; and Complex Interventions with Immigrants. The workshops were entrusted to six teachers: Three experienced social workers (two of them had responsibilities in organising social services) and three experts in social policies and interventions. To some extent, the expertise of these teachers helped us understand the quality and the interdisciplinary character of the programme. Moreover, the importance of experience-based learning was always stressed during training in the classroom, 
often with the participation of "testimonials" (coordinators, managers, and key figures in the system of social services) or professionals working in the area of social services. Finally, workshops were also designed in an integrated manner. They included traineeship activities and the preparation of a thesis. The aim was to give students an opportunity to do both theoretical and methodological work, that is to say, to learn social work theories and acquire the skills needed for interpreting the complex needs of people, managing services, and assessing the quality of such services. The workshops held by social workers gave students who were already social workers the possibility of doing second-level traineeship in specific areas. The workshops were intended to be an opportunity to gain an understanding of and explore social work interventions in some sectors. It was thought, in fact, that a learning approach based on the integration between social work theory and practice would make it possible to tackle the topics of the organisation of social services and policy and intervention assessment from a different but complementary perspective. The conviction was that social work theory should be built on specific research and investigation of social work practice from an interdisciplinary perspective.

The change, made necessary by the new legal provisions, promoted the introduction of a "specialistic" traineeship, valid for all students. As this traineeship did not consist of direct work with users, it provided a broader and integrated reading of social work, which included research activities, assessment, a systemic approach, and analysis and project development. Students compared notes with the persons in charge of services, decision makers, other professionals, researchers, and assessors. This integrated work was guided by a supervisor who had to have organisational duties in social services, which guaranteed a high-level traineeship. In this way, students coming from the Faculty of Sociology were expected to undertake practical research, for instance, on the organisation and system-wide implementation of a social secretariat, while social worker students could analyse the theoretical implications of social work when devising a social plan at a local level.

Then, the faculty decided to change the educational offering of traineeships in the Master's degree programme. However, the experience acquired seems to be an interesting case study of educational integration, a topic on which the following considerations are proposed.

\section{Is It Possible to Integrate Professional Skills in Social Work into a University Curriculum?}

To consider what type of knowledge is (or should be) taught and how it could be useful for professional social work means acknowledging the need to adjust and update such knowledge with the changes introduced in the welfare system by the "knowledge-based society" (as it is usually defined). In fact, authors, such as Wenger (1998), rightly argued that a social learning system was built by professionals, who worked as the "social containers" of the skills needed in social work. Wenger (1998) maintained that communities of professionals could grow by combining expertise and personal experience in a context of common practice. Hence, the interaction between professional expertise and scientific knowledge can create the best opportunities to enhance learning and innovation.

The experience of designing the Master's degree programme in social work offered by the Faculty of Sociology of Sapienza University of Rome, outlined in the previous section, suggests that combining professional expertise with scientific knowledge in the area of social services is feasible. Such an approach should focus on the development of social policies in the country, and most importantly, on the networks of relations that are intrinsic to work in the social sector.

Indeed, both practical experience and university reforms led to the design of a Master's degree programme that was intended to train specialised social workers, but also to educate future professionals who would have to 
tackle social work-related problems against a specific social and local background, while reflecting on organisational and professional issues. The designing of this course was an opportunity for defining the profile of a "manager" who could coordinate research and screening programmes in given catchment areas, monitor and assess the policy impacts of national and sub-national plans on the integrated organisation of services, and design a system of social intervention at a local level. In the educational offering, a key role was played by the traineeship experience within local assistance authorities, which was one of the logical links between the two cycles of the degree programmes. This traineeship was a way to involve students in issues related to organisation, management, assessment, research, and staff within the context of social work in a pragmatic and controlled manner.

If, as maintained by Reboul (1996), professional expertise was a complex level of learning and merging knowledge (hence theory, "knowing that...”) and skill levels (hence practice, "know-how”), teaching social work skills essentially would translate into training experts who should be able to address social work-related issues, as well as raise, construct, and solve a problem by correctly referring its context (Fabre, 1999). Hence, on the one hand, lecturers tried to educate the community of future professionals by helping them to reflect on shared rules, common resources, the language used, and their own routines. On the other hand, they focussed on the development processes that were necessary to increase professional skills. This implied that students were offered seminars and research experiences, in particular research aimed at assessing social work. Students were required to pursue their theoretical studies not by simply taking individual courses on any given subject, but by focussing on broader scientific approaches. Finally, they had to submit final dissertations that were aimed at understanding the complexities of social work and how to be a professional in social work.

The analysis of the academic programme conducted so far might be affected by a personal involvement. However, it can be argued that the intended educational message was straightforward and strong at the same time. A skill-based approach urged the social work community to develop knowledge as a way to think and act inside and outside the services. Trained social workers, the rest of the students, teaching professionals, and academics were all invited to use their knowledge in an integrated fashion when taking a decision, solving a problem, coping with a task, performing an analysis, defining a local project, and drafting a dissertation. Lecturers prompted students to exchange ideas by engaging them in active forms of teaching, based both on the research materials and the interaction and co-operation among students. For instance, students were invited to design their personal study environment in which, besides using a definite list of books, they could organise materials and training activities both in the classroom and "at home," in groups and individually. Moreover, the introduction of integrated educational modules provided lecturers with a teaching aid, even though it required a certain effort on their part, and helped students prepare for their tests, which were reduced in number. Three solutions were found to enhance didactic integration and an interdisciplinary approach. Firstly, exams provided for interactive activities, with more textbooks and materials covered in a single test. Secondly, teaching resources (lectures, textbooks, handouts, seminars, and lecturers) that could be associated either with a course, single classes, or a module. For instance, the same textbook could be assigned for several subjects. Thirdly, the programme including workshops and traineeships. In addition to what has already been discussed in the previous section, at the beginning of each workshop, students' proficiency levels and learning needs were identified by means of procedures that made it possible to set goals and consequently find the suitable teaching materials. Activities were all based on teaching units (each class was dedicated to a specific topic), with students working in couples/groups and with non-lecture methods. 
Experience seems to show that it is possible to achieve convergence of theoretical juxtapositions and overcome them. They are by no means neglected but, conversely, tackled and made instrumental to a learning process based on mastering interaction modalities and common socio-cultural tools (Allal, 1999). The presence of students with different educational backgrounds was not a barrier to learning. On the contrary, it enriched their education. Interdisciplinary skills and professional identity were intertwined, mainly through the participation and acknowledgement of the professional community. To sum up, 10 years' experience in coordinating the educational programme of the Master's degree in social work revealed a number of "mechanisms" that facilitated and characterised the educational offering addressed to social workers and other practitioners:

1. The unceasing opportunity to exchange ideas. Have a dialogue and discussions among lecturers and a direct communication channel with the Dean of the course, who regularly requested adjustments and changes, which were adopted in a participated and shared fashion;

2. The pressure to change the modes of university education, brought about by ministerial reforms and the will to define a way in the context of the city of Rome;

3. The need to meet the educational demand of practitioners, by engaging them in the new requests made by the students who were not social workers;

4. Frequent exchanges among academics, professionals, and the consultants and experts not belonging to academia or the profession, who offered their contribution to the analysis of contemporary social work, through seminars, research groups, open discussions, reports, papers, and public communications;

5. The will to continue (or engage in) research activities, by favouring specific training on issues of assessment and changes in the welfare systems and social services;

6. The collegial work within the group of lecturers and supervisors, as well as the appointment of a social worker acting as a tutor overseeing traineeships, with the support of the university traineeship co-ordinator (this was seen as an exclusive and privileged "space" for reflection on the profession, with the traineeships being assessed by supervisors and co-ordinators jointly).

\section{Final Considerations}

There are no other elements to assess this experience. However, considering the number of students who completed their studies in the allocated time, this integrated teaching approach seems to provide considerable advantages. The mechanisms listed above (but there may be others too) produced three effects in many students and certainly in most teachers. Firstly, there was a "learning effect," when the teaching programme (for instance, the integrated modules of several exams) led to new contents being introduced, sometimes through cooperation among lecturers (or students), or when students learned new professional tasks, even by readjusting prior knowledge. Secondly, there could be a "contrast effect," or a search for new learning and/or training methods, oriented towards a team, rather than a personal approach in defining contents and distributing tasks, or a generic redefinition of one's role and tasks. Thirdly, a "revaluation effect" was also identified, which translated into the ability to reconnect theoretical approaches and didactic contents with social work and policies. These led to a new educational method and style in social practice with its own operating modes (integrated modules, interdisciplinary workshops, shared programmes, interdisciplinary exams, and dissertations). The cultural and cognitive dimensions of professional social work issues were therefore enhanced. Students could experience their own roles as social workers, discuss the terms of their jobs, network 
with other colleagues (students and/or operators who were not social workers), co-operate, review modes of action, and meet operators with different backgrounds (sociologists, psychologists, researchers, etc.).

The integration between sociological theory and professional practice in the traineeships of the Master's degree programme of Sapienza University can also be construed in Bourdieu's terms (2005), as a set of "principles that generate and organise practices and representations that may be objectively suitable for their purpose without presupposing the conscious setting of goals and the explicit ownership of the operations necessary to achieve them, which are objectively 'regulated' and 'regular' without being produced through compliance with the rules.” The traineeship programme was presented to students as work that, in a real, practical, and relevant circumstance, helped them define the "habitus" of the social worker who translated sociological theory into practice and liaised with other professionals, and enabled professional identity to take shape in the service.

All in all, the educational experience of social policy specialists could be compared (and not juxtaposed) with that of social workers only by using the common ground of a type of social work that enhances different sources of knowledge, theory building through practice, and the formalisation of in-field experiences. The analysis of the Master's degree programme has identified those teaching conditions which somehow enabled integrated learning and the offering of different educational pathways, albeit in the single context (social work), which, as Fargion (2009) wrote, "takes the form of a wealth of stimuli and of a 'disorderly' setting that is open to several, even contradictory, interpretations and in which the outcomes of actions are never fully predictable.” The main sense not only of academia but also of professional social work seems to be the provision of educational opportunities in which the analytical reflection develops thoughtful and critical professionalism.

\section{References}

Allal, L. (1999). Acquisition et évaluation des compétences en situation scolaire (Acquisition and assessment of skills in school situations). In J. Dolz, \& E. Ollagnier (Eds.), L' énigme de la compétence en éducation (The Enigma of Competence in Education). Bruxelles: De Boeck.

Bourdieu, P. (2005). Il senso pratico (The practical sense). Roma: Armando.

Fabre, M. (1999). Epistemologia della formazione (Epistemology of education). Bologna: CLUEB.

Fargion, S. (2009). Il servizio sociale—Storia temi dibattiti (Social service—History, issues, and debates). Bari: Editori Laterza.

Reboul, O. (1996). Introduzione alla retorica (Introduction to rhetoric). Bologna: Il Mulino.

Wenger, E. (1998). Communities of practice: Learning, meaning, and identity. New York: Cambridge University Press. 